\title{
Technical Report: Method of Fixation of Subluxed or Dislocated Cervical Spine Below C1-C2
}

\section{H. H. TUCKER}

SUMMARY: A method of internal fixation of adjacent vertebrae that have been dislocated or subluxed has been presented. In the author's hands and in the hands of associates this has proven to be a satisfactory method of fixation in this type of injury. It has the advantage over many other posterior techniques that only two vertebrae are fixed together.

RÉSUMÉ: Une méthode de fixation interne des vertèbres adjacentes qui ont été disloquées ou subloxées est présentée. De l'avis de l'auteur et de ses associés, cette méthode s'est avérée être satisfaisante comme fixation pour ce type de blessure. Cette méthode a l'avantage par rapport à plusieurs autres techniques d'approche postérieure, de ne fixer que deux vertèbres.

* Now available from Codman and Shurtleff, Randolph, Mass. 02368

Reprint requests to Dr. H. H. Tucker, 135 MacBeth Avenue, Moncton, New Brunswick EIC 6 Z8 Canada.

From the Department of Neurosurgery, The Moncton Hospital, Moncton, N.B. Canada.

\section{HISTORICAL BACKGROUND}

Instability of the cervical spine below the $\mathrm{C} 1-\mathrm{C} 2$ level demonstrated by either persistent subluxation or dislocation requires some form of internal fixation (Alexander et al., 1967; Cloward, 1961). This may be done by different techniques. Wiring of the spinous processes of adjacent vertebrae after open reduction has been used (Alexander et al., 1967). Occasionally, wiring of the two spinous processes above the dislocation to the one below is used. Because of difficulty with wire breaking these procedures have often been reinforced by a posterior fusion. Using the Cloward technique (Metzler, 1974), some have been able to do the reduction of the dislocation and subluxation from in front, and have then done an anterior cervical fusion. In the author's experience using the anterior approach, there has been a tendency for the instability of the spine to allow for either pseudoarthrosis at the level of the fusion, or extrusion of the plug. Because of this, a method was devised twelve years ago to create an internal fixation of the spine using an interlaminar clamp* (Figure 1).

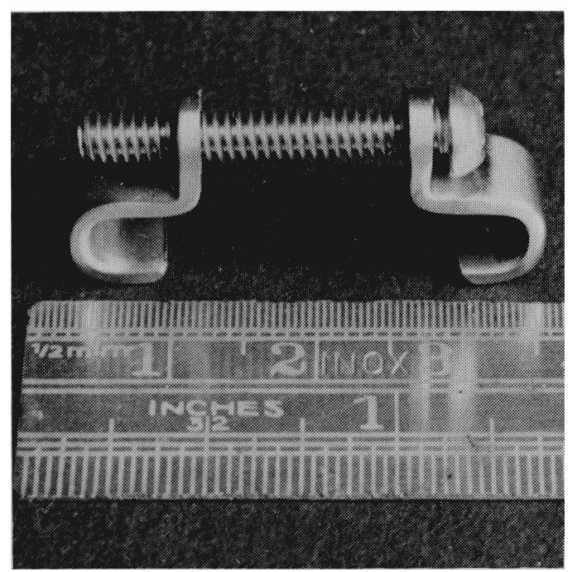

Figure 1

\section{MATERIAL}

Fifty-nine patients over the past twelve years have been operated on using the described method of internal fixation. This has resulted in adequate stabilization clinically, as well as radiologically.

\section{INDICATIONS}

Only patients with soft tissue damage plus dislocation or recurrent subluxation were selected for the procedure.

\section{TECHNIQUE}

Using skull traction and the prone position a posterior midline cervical incision was made. The laminae, spines and facet joints of the dislocated or subluxed vertebrae were exposed. Any persistent dislocation was reduced by an open technique. The articular surfaces of the facet joints were removed off the adjacent unstable vertebrae. Usually only one clamp was necessary, placed between the superior edge of the superior lamina on one side of the spinous process and the inferior margin of the inferior lamina on the same side (Figure 2). The bolt between the two segments of the clamp was used to close the jaws of the clamp until the vertebrae were fixed firmly together and moved as one solid unit and the facet joints were closed.

\section{COMPLICATIONS}

Of the fifty-nine patients operated on, two complications were seen. In one case, an infection of the wound made it necessary to remove the clamp because the foreign body was involved in the infected area. The only other complication was a missed fracture in the pedicle on the side opposite to the side that was clamped. The superior vertebra then 


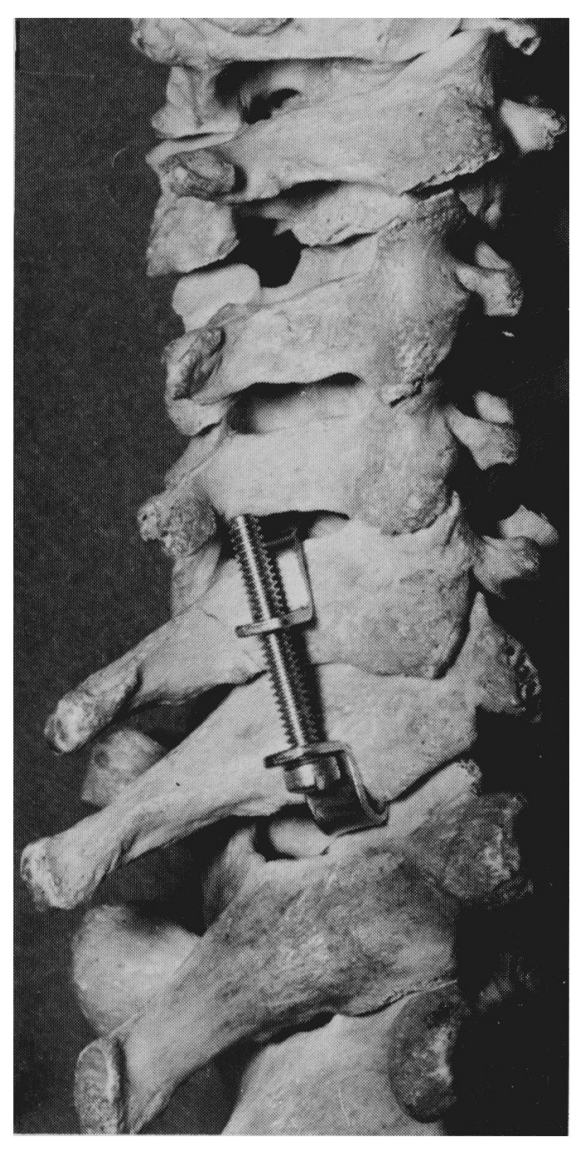

Figure 2 rotated on the clamp, using the clamp as a fulcrum. There was a recurrent unilateral dislocation on the side opposite to the clamp. If the fracture had been identified at the time of surgery, a double clamping technique would have been used which should have given the stability required. However, since it was not, anterior fusion was done secondarily according to the Cloward technique (1961) and this proved to be satisfactory.

\section{RESULTS}

In the other fifty-seven patients, one additional clamp had to be removed because of a suspected infection. This proved to be a deep cervical abscess, and by the time it was realized that the abscess had no connection with the clamp the adjacent area had been opened up and it was advisable to remove it. Of the fifty-six remaining cases, the results were satisfactory clinically and radiologically. Most of these patients developed a fusion across the facet joints. Those with additional tears of the anterior longitudinal ligament (unidentified at the time of the original problem) developed some fusion between the bodies as well. One patient had an interlaminar clamp placed and sustained a subsequent injury to his neck with dislocation at the space below the level of his previously placed clamp. At the time of surgery the clamp was solidly in place, and there was a definite fusion of the facet joints.

\section{REFERENCES}

ALEXANDER, EBEN, COURTLAND, H. DAVIS JR., and H. FRANCIS FORSYTH, (1967). Reduction and Fusion of Fracture Dislocations of the Cervical Spine - The Journal of Neurosurgery, Vol. 27, page 588-591.

CLOWARD, RALPH B. (1961). Treatment of Acute Fractures and Fracture Dislocations of the Cervical Spine by Vertebral Body Fusion - The Journal of Neurosurgery, Vol. 18, page 201-209.

METZLER, WM. Orthopaedics Vol. 2, pages 6-18; Hagerstown, Maryland, New York, London, 1974. 